\title{
Commentary: Poking the right ventricle for a diagnosis-Proceed with caution
}

Ibrahim Sultan, MD

\footnotetext{
From the Division of Cardiac Surgery, Department of Cardiothoracic Surgery, University of Pittsburgh, Pittsburgh, Pa; and Heart and Vascular Institute, University of Pittsburgh Medical Center, Pittsburgh, Pa. Disclosures: Author has nothing to disclose with regard to commercial support.

Received for publication June 6, 2019; accepted for publication June 7, 2019; available ahead of print July 23, 2019.

Address for reprints: Ibrahim Sultan, MD, Division of Cardiac Surgery, 5200 Centre Ave, Suite 715, Pittsburgh, PA 15232 (E-mail: sultani@upmc.edu).

J Thorac Cardiovasc Surg 2020;159:e119 $0022-5223 / \$ 36.00$

Copyright (C) 2019 by The American Association for Thoracic Surgery https://doi.org/10.1016/j.jtcvs.2019.06.027
}

Intracardiac tumors can be asymptomatic at an early stage and may be quite large or unresectable before symptoms appear. Tissue diagnosis can be critical in these patients with unresectable disease, and sternotomy or thoracotomy may delay definitive chemoradiation. In this issue of the Journal, Burkett and colleagues ${ }^{1}$ present their technique of computed tomographically guided transthoracic biopsy of the right ventricular outflow tract. Their patient was seen with recurrence in the right ventricular outflow tract after a partial hepatectomy for hepatocellular carcinoma.

Although catheter directed biopsies of the heart are standard of care, this transthoracic technique is uncommon. Burkett and colleagues ${ }^{1}$ are to be congratulated for a successful and a safe procedure. A procedure like this can be fraught with complications, however, and preparations to avoid these are important. Potential complications include fatal arrythmias, hemopericardium, and hemopneumothorax. Epicardial pads can ensure rapid defibrillation in the setting of an unstable arrythmia, and a postprocedure hemopneumothorax can be diagnosed with a portable chest radiograph. An echocardiogram should be readily available to rule out a pericardial effusion. Clinical judgment is critical in these scenarios, in which patients may decompensate relatively rapidly, and hemodynamic monitoring with an arterial line can be invaluable.

Although the technique of Burkett and colleagues ${ }^{1}$ is useful and should be available in the armamentarium of interventional radiologists, it is prudent to use endomyocardial biopsy as the first line among diagnostic tools. Most biopsies can be successfully performed this way with

\section{References} tion. 2013;128:1790-4.

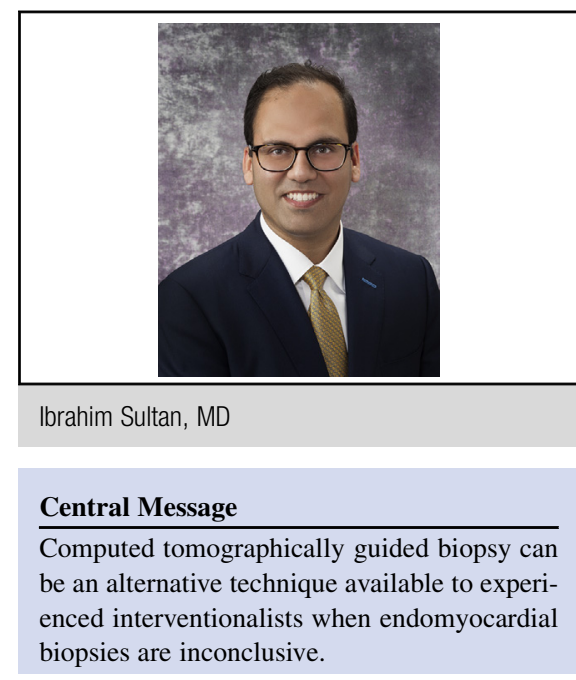

See Article page e115.

adequate tissue sampling, and the procedure carries a significantly lower risk profile.

Most tumors of the heart are metastatic in nature, and they may be present in as many as $9 \%$ of patients with known malignancies. ${ }^{2}$ Nearly a third of these tumors are pericardial in nature, however, followed by epicardial and myocardial involvement. Most of the pericardial base metastases (effusions) can be readily sampled with pericardiocentesis. Intracavitary and endocardial metastases are rare and constitute a small percentage of cardiac metastases. Many of these metastases are diagnosed during the routine imaging surveillance that patients with malignancies undergo. Prompt diagnosis with techniques such as that described by Burkett and colleagues ${ }^{1}$ may help in determining best therapeutic options for our patients.

1. Burkett BJ, Arghami A, Bois MC, Breen JF, Young JR. Computed tomographically guided transthoracic biopsy of a cardiac mass in the right ventricular outflow tract. J Thorac Cardiovasc Surg. 2020;159:e115-8.

2. Goldberg AD, Blankstein R, Padera RF. Tumors metastatic to the heart. Circula- 